\title{
Medicare/Medicaid Insurance, Rurality, and Black Race Associated With Provision of Hepatocellular Carcinoma Treatment and Survival
}

Andrew M. Moon, MD, MPH ${ }^{1, \star}$; Hanna K. Sanoff, MD, MPH',3,*; YunKyung Chang, PhD³; Jennifer L. Lund, PhD ${ }^{3,4}$; A. Sidney Barritt IV, MD, MSCR ${ }^{1}$; Paul H. Hayashi, MD, MPH'; and Karyn B. Stitzenberg, MD, MPH 3,5

\section{ABSTRACT}

Background: Early treatment of hepatocellular carcinoma (HCC) is associated with improved survival, but many patients with $\mathrm{HCC}$ do not receive therapy. We aimed to examine factors associated with $\mathrm{HCC}$ treatment and survival among incident patients with $\mathrm{HCC}$ in a statewide cancer registry. Materials and Methods: All patients with HCC from 2003 through 2013 were identified in the North Carolina cancer registry. These patients were linked to insurance claims from Medicare, Medicaid, and large private insurers in North Carolina. Associations between prespecified covariates and more advanced HCC stage at diagnosis (ie, multifocal cancer), care at a liver transplant center, and provision of HCC treatment were examined using multivariate logistic regression. A Cox proportional hazards model was developed to assess the association between these factors and survival. Results: Of 1,809 patients with HCC, $53 \%$ were seen at a transplant center $<90$ days from diagnosis, with lower odds among those who were Black (adjusted odds ratio [aOR], 0.54; 95\% Cl, 0.39-0.74), had Medicare insurance (aOR, 0.35; $95 \% \mathrm{Cl}, 0.21-0.59$ ), had Medicaid insurance (aOR, 0.46;95\% Cl, $0.28-0.77$ ), and lived in a rural area; odds of transplant center visits were higher among those who had prediagnosis alpha fetoprotein screening (aOR, 1.74; 95\% Cl, 1.35-2.23) and PCP and gastroenterology care (aOR, 1.66; 95\% Cl, 1.27-2.18). Treatment was more likely among patients who had prediagnosis gastroenterology care $(\mathrm{aOR}, 1.68 ; 95 \%$ $\mathrm{Cl}, 0.98-2.86)$ and transplant center visits $(a O R, 2.42 ; 95 \% \mathrm{Cl}$, 1.74-3.36). Survival was strongly associated with age, cancer stage, cirrhosis complications, and receipt of HCC treatment. Individuals with Medicare (adjusted hazard ratio [aHR], 1.58; 95\% Cl, 1.20-2.09) and Medicaid insurance (aHR, 1.55; 95\% Cl, 1.17-2.05) had shorter survival than those with private insurance. Conclusions: In this population-based cohort of patients with HCC, Medicare/Medicaid insurance, rural residence, and Black race were associated with lower provision of HCC treatment and poorer survival. Efforts should be made to improve access to care for these vulnerable populations.

J Natl Compr Canc Netw 2021;19(3):285-293 doi: $10.6004 /$ jnccn.2020.7616

${ }^{1}$ Division of Gastroenterology and Hepatology, Department of Medicine, and ${ }^{2}$ Division of Hematology/Oncology, Department of Medicine; ${ }^{3}$ Lineberger Comprehensive Cancer Center; ${ }^{4}$ Center for Pharmacoepidemiology,

Department of Epidemiology; and ${ }^{5}$ Division of Surgical Oncology, Department of Surgery, University of North Carolina, Chapel Hill, North Carolina.

\section{Background}

Hepatocellular carcinoma (HCC) incidence and mortality are increasing in the United States. ${ }^{1,2}$ The prognosis for HCC is poor, in part because potentially curative treatments, including surgical resection, ablation, and transplantation, are feasible in just a minority of patients with early-stage HCC. ${ }^{3}$ In the absence of curative therapy, liver-directed locoregional therapies and drug therapy prolong survival, yet up to half of all patients with HCC never receive any cancer-directed therapy. ${ }^{4-7}$

Despite accumulating evidence that the provision of timely HCC treatment decreases cancer-related mortality, ${ }^{8}$ treatment rates remain low and the reasons for nonreceipt of therapy in patients with HCC remain unclear. Medical comorbidities, decompensated liver disease, and advanced HCC often preclude specific HCC-directed therapies. Other potential factors have been associated with the low provision of HCC therapy, including older patient age, insurance status, and care at a low-volume center. ${ }^{9-11}$ In addition, racial and ethnic disparities in the receipt of HCC treatment and survival have been welldocumented. ${ }^{12-16}$ Finally, subspecialist consultation has been associated with improved treatment outcomes in the US Department of Veterans Affairs system. ${ }^{17}$ This evidence suggests that both patient- and facility-level factors likely influence the provision of HCC treatment. However, relatively few data sources allow for the simultaneous investigation of these many potential variables in a population-based sample.

We therefore assessed the potential predictors of advanced cancer, care at a transplant center, provision of treatment, and mortality among patients from a population-based state registry linked to insurance claims data.

See JNCCN.org for supplemental online content.

*These authors contributed equally to this study. 


\section{Materials and Methods}

This work was approved by the Biomedical Institutional Review Board at the University of North Carolina (\#12-1828).

\section{Patients}

The cohort comprised patients diagnosed with HCC in 2003 through 2013, identified from the North Carolina Central Cancer Registry (NCCCR) by ICD-10 code C22.0 and ICD-O-3 histology codes 8170-8175 and 8180. These patients were linked to insurance claims from Medicare, Medicaid, and large private insurance providers in North Carolina by the UNC Lineberger Cancer Information \& Population Health Resource. ${ }^{18}$ This subset consisted of patients with continuous healthcare enrollment in any health plan for 12 months preceding and 12 months after diagnosis (or death). Patients participating in a Medicare $\mathrm{HMO} /$ Advantage plan were excluded because claims are not required to be reported to Medicare.

To evaluate factors associated with treatment and survival, only patients surviving the 90-day exposure window after diagnosis were included in multivariable models, thereby including only patients who may have been eligible for treatment.

\section{Covariates}

Patient age, sex, marital status, race, county and zip code of residence, and insurance status at diagnosis were derived from the NCCCR demographics file. We used the NCCCR collaborative staging extension variables of number of tumors and presence/absence of vascular invasion to group cancers into clinically meaningful categories (ie, single or multiple, with or without vascular invasion, and extrahepatic disease). Multifocal cancer was defined as the presence of multiple intrahepatic tumors with or without vascular spread, extrahepatic spread, or unstaged HCC. As has been done in previous studies of HCC outcomes using claims data, ${ }^{5}$ unstaged HCC was considered together with extrahepatic spread given the similar outcomes among these groups. These categories are similar to the tumor extent component of the Barcelona Clinic Liver Cancer staging system and approximate patients who may qualify for liver transplantation, surgical resection, or locoregional therapies..$^{19,20}$

County-level economic and healthcare covariates were taken from the Area Health Resources File ${ }^{21}$ and the North Carolina Health Professions Data System (https://nchealthworkforce.unc.edu/). Measures were selected to cover domains used in other composite measures of census tract-based socioeconomic status. ${ }^{22-24}$ Given the large number of covariates measured across 100
North Carolina counties, we used factor analysis to create representative indices. Factor analysis was conducted separately for health system factors that together had an average variance extracted of $58 \%$ across counties and for economic factors (see supplemental eTable 1, available with this article at JNCCN.org). For economic variables, 2 factors combined for an average variance extracted of $83.2 \%$ across counties. The first factor was described as an economic disadvantage index because it was dominated by median home value, percentage of White patients, and unemployment rate. The second was described as the rurality index because it was dominated by level of rurality and percentage of agricultural/forestry/hunting/mining industries. For each index, the lowest quartile described the least disadvantaged patients according to these measures.

Additional patient-level covariates were determined from ICD-9 claims in the 12 months prediagnosis, including nonliver comorbidity using the Klaubunde modification of the Charlson-Deyo comorbidity index (excluding liver disease), ${ }^{25}$ psychiatric comorbidity not including substance abuse (eg, depression, anxiety, bipolar disorder, schizophrenia, posttraumatic stress disorder), liver-related complications (eg, encephalopathy, ascites, varices, hepatorenal syndrome), ${ }^{26}$ and underlying cause of liver disease. Because many patients had low healthcare utilization in the year before diagnosis, codes for the cause of liver disease were evaluated from 12 months before diagnosis to 1 month after diagnosis.

Prediagnosis healthcare utilization was determined by visits with a primary care provider or gastroenterology/ hepatology provider in the year before diagnosis (excluding 2 months prediagnosis, when consultations may reflect referrals for cancer), prediagnosis alpha fetoprotein (AFP) screening ${ }^{27}$ (American Association for the Study of Liver Diseases guidelines recommended every 6 months during this era for patients with cirrhosis and hepatitis virus), ${ }^{28}$ and number of unique contacts with the healthcare system (inpatient or outpatient visits). Consultation with HCC-specific subspecialty clinicians and at a liver transplant center was measured in the 90 days after diagnosis. Distance from each patient's zip code to the closest liver transplant center was calculated. Treatment was defined as the initial treatment received as described in earlier research, ${ }^{5}$ acknowledging that many patients go on to receive multiple therapies.

\section{Analysis}

We extracted patient- and county-level factors for all patients with HCC and linked claims data, and performed univariate analyses on demographic characteristics, insurance status, socioeconomic status, rurality, 
medical/psychiatric comorbidities, liver disease etiology and complications, and cancer stage at diagnosis, calculating the median and interquartile range (IQR) for continuous variables and proportions for categorical variables. We calculated annual rates for subspecialty consultation within 90 days of HCC diagnosis and provision of HCC treatments. Multivariable logistic regression analysis was used to assess the variables associated with multifocal cancer at diagnosis, transplant center visits, and provision of HCC treatments. Finally, we developed a Cox proportional hazards model to assess variables associated with overall survival. All statistical analyses were performed with SAS 9.4 (SAS Institute Inc).

\section{Results}

\section{Cohort Description}

Our cohort included 1,809 patients with HCC (supplemental eFigure 1 and eTable 2). Most patients had single $(37 \%)$ or multiple $(25 \%)$ tumors without vascular invasion or extrahepatic spread. A smaller proportion had vascular spread at diagnosis, including $6 \%$ and $13 \%$ of those with single and multiple lesions, respectively. Median age was 68 years (IQR, 59-76 years) and patients were predominantly male $(73 \%)$, White $(76 \%)$, and had Medicare insurance (59\%).

\section{Multifocal HCC at Diagnosis}

A total of 1,033 patients (57\%) had multifocal HCC at presentation. Multifocal cancer at presentation was significantly associated with age, marital status, and sex. Receipt of prediagnosis AFP screening (adjusted odds ratio [aOR], 0.72; 95\% CI, 0.58-0.90) and PCP and gastroenterology/hepatology care (aOR, 0.77; 95\% CI, 0.61-0.96) was associated with decreased odds of multifocal disease (Table 2).

\section{Visits to a Liver Transplant Center}

In the 90 days after diagnosis, 957 (53\%) of patients were seen at a liver transplant center for any reason (Figure 1 and eTable 3). A transplant center visit was significantly less likely among patients who were older (age $\geq 75$ vs $<50$ years: aOR, 0.52; 95\% CI, 0.28-0.94), Black (vs White: aOR, 0.54; 95\% CI, 0.39-0.74), insured by Medicare (vs private insurance: aOR, 0.35; 95\% CI, 0.21-0.59), and insured by Medicaid/dual (vs private insurance: aOR, $0.46 ; 95 \% \mathrm{CI}$, 0.28-0.77).

Patients residing a median of 53 miles (aOR, 0.46; 95\% CI, 0.32-0.66) and 106 miles (aOR, 0.27; 95\% CI, 0.18-0.41) from the closest transplant center were less likely to have visited a transplant center than those living in the closest tertile (median, 17.4 miles). Transplant center visits were also less likely among those living in the most rural counties (vs least rural: aOR, 0.24; 95\% CI,
0.14-0.47). Prediagnosis healthcare was also a major determinant of transplant center visit, with increased odds among patients with more prediagnosis healthcare utilization (highest vs lowest tertile: aOR, 2.14; 95\% CI, 1.57-2.93), AFP screening (aOR, 1.74; 95\% CI, 1.35-2.23), and gastroenterology/hepatology care (aOR, 1.66; 95\% CI, 1.27-2.18).

\section{Provision of HCC Treatment}

Of the 1,809 patients with HCC, $30 \%$ died within the 90-day treatment exposure window after diagnosis and were excluded from treatment and survival analyses. These patients were older (ie, more likely to be aged $\geq 75$ years), had greater comorbidity, had more advanced cancer, were more likely to be divorced, and were less likely to have received prediagnosis care. They were significantly less likely to be seen at a transplant center or to have received treatment for their HCC.

In the 1,250 patients surviving the 90-day treatment exposure window, 857 (69\%) were treated (Table 1). The types of treatments used over time can be seen in Figure 2. Of these patients, $478(56 \%)$ had a surgical consultation, $425(50 \%)$ had a gastroenterology/hepatology consultation, and 469 (55\%) saw a hematologist/ oncologist; these rates slowly increased from 2003 to 2013 (Figure 1).

Factors most strongly associated with receipt of HCC treatment included prediagnosis AFP screening (aOR, 2.61; 95\% CI, 1.90-3.60), surgical consultation (aOR, 3.40; $95 \% \mathrm{CI}, 2.48-4.67)$, and visit to a liver transplant center (aOR, 2.42; 95\% CI, 1.74-3.36) (Table 1). In contrast, advanced age (65-74 or $\geq 75$ years), unmarried status, psychiatric comorbidity, and liver-related complications all significantly reduced the odds of receiving HCC treatment.

\section{Overall Survival}

Across the study period, survival increased from a median of 6 months (IQR, 2-21) in 2004 through 2006 to 8 months (IQR, 2-28) in 2010 through 2012. In adjusted models accounting for disease severity and treatment, patients diagnosed in 2008 and beyond had significantly better survival than those diagnosed in 2004 through 2007 (adjusted hazard ratio [aHR] for death, 0.75; 95\% CI, 0.66-0.85).

In addition to year of diagnosis, cancer stage and receipt of cancer treatment were strongly associated with survival. Compared with the $12 \%$ of patients who underwent curative surgery, risk of death was higher among those treated with ablation (aHR, 1.60; 95\% CI, 1.20-2.13) and locoregional therapy (aHR, 2.47; 95\% CI, 1.90-3.19). Patients treated with drug therapy (aHR, 4.57; 95\% CI, 3.27-6.40) or radiation (aHR, 3.79; 95\% CI, 2.55-5.65) and those who were untreated (aHR, 4.97; 95\% CI, 3.79-6.51) 
Table 1. Factors Associated With Treatment Among Patients Surviving 90 Days From Diagnosis $(\mathrm{N}=1,250)$

\begin{tabular}{|c|c|c|c|c|}
\hline \multirow[b]{2}{*}{ Characteristic } & \multirow{2}{*}{$\begin{array}{c}\text { Treated } \\
\mathbf{n}(\%)\end{array}$} & \multirow{2}{*}{$\begin{array}{c}\text { Untreated } \\
n(\%)\end{array}$} & \multicolumn{2}{|c|}{ Odds of Treatment ${ }^{a}$} \\
\hline & & & OR $(95 \% \mathrm{Cl})$ & aOR $(95 \% \mathrm{Cl})$ \\
\hline Patients, $\mathrm{n}$ & 857 (69) & $393(31)$ & & \\
\hline \multicolumn{5}{|l|}{ Initial treatment } \\
\hline Curative surgery & $149(12)$ & - & - & - \\
\hline Ablation & $186(15)$ & - & - & - \\
\hline LRT (TACE + TARE) & $387(31)$ & - & - & - \\
\hline Drug therapy & $89(7)$ & - & - & - \\
\hline Radiation & $46(4)$ & - & - & - \\
\hline \multicolumn{5}{|l|}{ Year of diagnosis } \\
\hline 2004-2005 & $162(19)$ & $78(20)$ & Ref & Ref \\
\hline 2006-2007 & $160(19)$ & 75 (19) & $1.03(0.70-1.51)$ & $0.91(0.58-1.44)$ \\
\hline 2008-2009 & $200(23)$ & $101(26)$ & $0.95(0.66-1.37)$ & $0.86(0.56-1.33)$ \\
\hline 2010-2011 & $208(24)$ & $77(20)$ & $1.30(0.89-1.89)$ & $1.33(0.85-2.07)$ \\
\hline $2012-2013$ & $127(15)$ & $62(16)$ & $0.99(0.66-1.48)$ & $1.09(0.65-1.82)$ \\
\hline \multicolumn{5}{|l|}{ Median age, y } \\
\hline$<65$ & $382(45)$ & $134(34)$ & Ref & Ref \\
\hline $65-74$ & $306(36)$ & $112(28)$ & $0.96(0.72-1.28)$ & $0.64(0.41-0.99)$ \\
\hline$\geq 75$ & $169(20)$ & $147(37)$ & $0.40(0.30-0.54)$ & $0.30(0.18-0.49)$ \\
\hline \multicolumn{5}{|l|}{ Race } \\
\hline White & $661(77)$ & $289(74)$ & Ref & Ref \\
\hline Black & $162(19)$ & $92(23)$ & $0.77(0.58-1.03)$ & $0.84(0.56-1.24)$ \\
\hline Other & $34(4)$ & $12(3)$ & $1.24(0.63-2.43)$ & $1.42(0.64-3.18)$ \\
\hline \multicolumn{5}{|l|}{ Marital status } \\
\hline Married & $415(48)$ & $150(38)$ & Ref & Ref \\
\hline Divorced/Separated/Single & $239(28)$ & $173(44)$ & $0.53(0.41-0.69)$ & $0.62(0.44-0.88)$ \\
\hline Other/Unknown & $203(24)$ & $70(18)$ & $0.99(0.71-1.38)$ & $0.81(0.53-1.22)$ \\
\hline \multicolumn{5}{|l|}{ Insurance at diagnosis } \\
\hline Private & $117(14)$ & $18(5)$ & Ref & Ref \\
\hline Medicare & $478(56)$ & $233(59)$ & $0.32(0.19-0.53)$ & $0.78(0.40-1.50)$ \\
\hline Medicaid/Dual & $262(31)$ & $142(36)$ & $0.28(0.17-0.49)$ & $0.80(0.41-1.54)$ \\
\hline \multicolumn{5}{|l|}{ Psychiatric comorbidity } \\
\hline No & $488(57)$ & $192(49)$ & Ref & Ref \\
\hline Yes & $369(43)$ & $201(51)$ & $0.72(0.57-0.92)$ & $0.64(0.47-0.89)$ \\
\hline \multicolumn{5}{|l|}{$\mathrm{CCl}$ score } \\
\hline 0 & $354(41)$ & $140(36)$ & Ref & Ref \\
\hline 1 & $266(31)$ & $108(27)$ & $0.97(0.72-1.31)$ & $0.90(0.63-1.30)$ \\
\hline$\geq 2$ & $237(28)$ & $145(37)$ & $0.65(0.49-0.86)$ & $0.78(0.54-1.12)$ \\
\hline \multicolumn{5}{|l|}{ Liver-related complications } \\
\hline 0 & $561(65)$ & $250(64)$ & Ref & Ref \\
\hline$\geq 1$ & $296(35)$ & $143(36)$ & $0.92(0.72-1.18)$ & $0.51(0.35-0.74)$ \\
\hline
\end{tabular}


Table 1. Factors Associated With Treatment Among Patients Surviving 90 Days From Diagnosis (cont.)

\begin{tabular}{|c|c|c|c|c|}
\hline \multirow[b]{2}{*}{ Characteristic } & \multirow{2}{*}{$\begin{array}{c}\text { Treated } \\
\text { n (\%) }\end{array}$} & \multirow{2}{*}{$\begin{array}{c}\text { Untreated } \\
\text { n (\%) }\end{array}$} & \multicolumn{2}{|c|}{ Odds of Treatment ${ }^{a}$} \\
\hline & & & OR $(95 \% \mathrm{Cl})$ & aOR $(95 \% \mathrm{Cl})$ \\
\hline \multicolumn{5}{|l|}{ Cancer extension } \\
\hline Single with vascular invasion & $59(7)$ & $28(7)$ & $0.72(0.44-1.19)$ & $0.69(0.38-1.24)$ \\
\hline Multiple without vascular invasion & $249(29)$ & $87(22)$ & $0.98(0.72-1.35)$ & $1.07(0.74-1.54)$ \\
\hline Extrahepatic & $20(2)$ & $15(4)$ & $0.46(0.23-0.92)$ & $0.43(0.19-0.99)$ \\
\hline Not staged & $66(8)$ & $82(21)$ & $0.28(0.19-0.41)$ & $0.43(0.28-0.68)$ \\
\hline \multicolumn{5}{|l|}{1 y prediagnosis specialty care } \\
\hline None & $86(10)$ & $65(17)$ & Ref & Ref \\
\hline PCP only & $412(48)$ & $225(57)$ & $1.38(0.96-1.99)$ & $1.36(0.85-2.17)$ \\
\hline Yes & $503(59)$ & $126(32)$ & $3.01(2.34-3.87)$ & $2.61(1.90-3.60)$ \\
\hline \multicolumn{5}{|l|}{ Surgical consult 90 days after diagnosis } \\
\hline No & $379(44)$ & $295(75)$ & Ref & Ref \\
\hline Yes & $478(56)$ & $98(25)$ & $3.80(2.91-4.95)$ & $3.40(2.48-4.67)$ \\
\hline \multicolumn{5}{|c|}{ Visit to liver transplant center 90 days from diagnosis } \\
\hline Yes & $659(77)$ & $183(47)$ & $3.54(2.76-4.54)$ & $2.42(1.74-3.36)$ \\
\hline No & $198(23)$ & $210(53)$ & Ref & Ref \\
\hline \multicolumn{5}{|l|}{ County economic disadvantage index } \\
\hline Q1: least disadvantaged & $175(20)$ & $66(17)$ & Ref & Ref \\
\hline Q3 & $139(16)$ & $64(16)$ & $0.94(0.67-1.32)$ & $0.70(0.45-1.11)$ \\
\hline Q4: most rural & $54(6)$ & $34(9)$ & $0.69(0.44-1.09)$ & $0.70(0.37-1.33)$ \\
\hline
\end{tabular}

Abbreviations: AFP, alpha fetoprotein; aOR, adjusted odds ratio; CCl, Charlson-Deyo comorbidity index; GE, gastroenterology; LRT, locoregional therapies; OR, odds ratio; PCP, primary care physician; TACE, transarterial chemoembolization; TARE, transarterial radioembolization; $\mathrm{Q}$, quartile.

aModel was also adjusted for sex, cause of liver disease, prediagnosis healthcare utilization, postdiagnosis GE/hepatology and hematology/oncology consultation, and county health services index, which were not significantly associated with survival with minimal/no trend suggesting possible effect. These variables were omitted to condense the table size.

had a higher risk of mortality, although these results were not adjusted for factors that may influence treatment selection (eg, bilirubin level) (Table 2).

Survival was better among younger patients (aged $<55$ years) and those without comorbidities. Receipt of prediagnosis gastroenterology/hepatology care was associated with improved survival compared with patients who saw neither a primary care nor a gastroenterology/hepatology physician in the year before diagnosis (aHR, 0.74; 95\% CI, 0.58-0.94). Despite adjusting for age and treatment received, patients with Medicare (aHR, 1.58; 95\% CI, 1.20-2.09) and Medicaid/dual (aHR, 1.55; 95\% CI, $1.17-2.05$ ) had significantly worse survival than those with private insurance (Table 2).

\section{Discussion}

In this population-based retrospective cohort study examining the effects of patient characteristics, county-level resources, and healthcare utilization on HCC outcomes, we found patient-level sociodemographic factors (age 


\begin{tabular}{|c|c|c|c|}
\hline \multirow[b]{2}{*}{ Patient-Level Characteristic } & \multirow{2}{*}{$\begin{array}{l}\text { Patients Surviving } \\
90 \text { Days } \\
\text { n (\%) }\end{array}$} & \multicolumn{2}{|c|}{ Hazard for Mortality } \\
\hline & & HR $(95 \% \mathrm{Cl})$ & aHR $(95 \% \mathrm{Cl})$ \\
\hline \multicolumn{4}{|l|}{ Year } \\
\hline 2004-2007 & $475(38)$ & Ref & Ref \\
\hline 2008-2013 & $775(62)$ & $0.85(0.75-0.97)$ & $0.75(0.66-0.85)$ \\
\hline \multicolumn{4}{|l|}{ Age, y } \\
\hline$<50$ & $93(7)$ & Ref & Ref \\
\hline $50-64$ & $423(34)$ & $0.97(0.76-1.26)$ & $1.08(0.83-1.40)$ \\
\hline $65-74$ & $418(33)$ & $1.32(1.02-1.69)$ & $1.34(1.00-1.78)$ \\
\hline$\geq 75$ & $316(25)$ & $1.48(1.15-1.92)$ & $1.39(1.03-1.87)$ \\
\hline \multicolumn{4}{|l|}{ Race } \\
\hline White & $950(76)$ & Ref & Ref \\
\hline Black & $254(20)$ & $1.09(0.94-1.27)$ & $1.09(0.91-1.30)$ \\
\hline Other & $46(4)$ & $0.92(0.66-1.28)$ & $1.40(0.98-1.99)$ \\
\hline \multicolumn{4}{|l|}{ Insurance at diagnosis } \\
\hline Private & $135(11)$ & Ref & Ref \\
\hline Medicare & $711(57)$ & $2.31(1.82-2.93)$ & $1.58(1.20-2.09)$ \\
\hline Medicaid/Dual & $404(32)$ & $2.50(1.95-3.20)$ & $1.55(1.17-2.05)$ \\
\hline \multicolumn{4}{|l|}{ Psychiatric comorbidity } \\
\hline No & $680(54)$ & Ref & Ref \\
\hline Yes & $570(46)$ & $1.16(1.03-1.31)$ & $1.15(1.00-1.32)$ \\
\hline \multicolumn{4}{|l|}{$\mathrm{CCl}$ score } \\
\hline 0 & $494(40)$ & Ref & Ref \\
\hline 1 & $374(30)$ & $1.18(1.02-1.36)$ & $1.14(0.97-1.33)$ \\
\hline$\geq 2$ & $382(31)$ & $1.40(1.21-1.62)$ & $1.18(1.00-1.38)$ \\
\hline
\end{tabular}

$>65$ years, Black race, unmarried status, type of insurance) to be key determinants of stage at diagnosis and survival after an HCC diagnosis. These same patient factors were associated with liver transplant center visits and cancer-directed treatment. When further analyzing the root causes, we found that survival was most strongly associated with receipt of cancer-directed treatment. Treatment in turn was more likely in patients with prediagnosis gastroenterology/hepatology specialty care and AFP screening and with postdiagnosis liver transplant center visits, which are likely a surrogate for receipt of multidisciplinary care. The disparities in outcomes were therefore largely accounted for by lower-quality healthcare before and after an HCC diagnosis. In all analyses, Medicaid and Medicare beneficiaries experienced significantly inferior outcomes, including a marked reduction in survival, compared with patients who were privately insured.

Given that HCC incidence is higher among racial and ethnic minorities and in socioeconomically disadvantaged regions, ${ }^{29,30}$ we hypothesized that a lack of access to local healthcare resources and greater socioeconomic status disadvantage are key contributing factors to the low rates of treatment and the disparities in care that have been previously reported. After investigating a wide array of county-level determinants of economic health and healthcare availability, we found that the only clear associations between county factors and quality of HCC care were that patients residing in the most rural counties and counties farthest from a transplant center were least likely to be seen at a transplant center in the 90 days after diagnosis. No other county-level factors clearly influenced treatment or survival among patients with HCC.

Health insurance was strongly associated with the likelihood of transplant center visits and survival. The association between Medicare insurance and these outcomes could be confounded by age, given that Medicare beneficiaries are usually aged $>65$ years and some patients may be ineligible for liver transplantation based on advanced age. However, recent data suggest that an increased proportion of patients with HCC 


\begin{tabular}{|c|c|c|c|}
\hline Patient-Level Characteristic & $\begin{array}{c}\text { Patients Surviving } \\
90 \text { Days } \\
\text { n (\%) }\end{array}$ & HR $(95 \% \mathrm{CI})$ & aHR $(95 \% \mathrm{Cl})$ \\
\hline \multicolumn{4}{|l|}{ Liver-related complications } \\
\hline 0 & $811(65)$ & Ref & Ref \\
\hline$\geq 1$ & $439(35)$ & $1.00(0.88-1.14)$ & $1.24(1.05-1.45)$ \\
\hline Single lesion & $591(47)$ & Ref & Ref \\
\hline Multiple without vascular invasion & $336(27)$ & $1.51(1.31-1.75)$ & $1.41(1.21-1.64)$ \\
\hline Multiple with vascular invasion & $140(11)$ & $2.18(1.79-2.66)$ & $1.74(1.42-2.14)$ \\
\hline Extrahepatic/Not staged & $183(15)$ & $2.05(1.71-2.44)$ & $1.39(1.15-1.69)$ \\
\hline Drug therapy (including sorafenib) & $89(7)$ & $5.81(4.28-7.90)$ & $4.57(3.27-6.40)$ \\
\hline Radiation & $46(4)$ & $4.49(3.10-6.49)$ & $3.79(2.55-5.65)$ \\
\hline Never treated & $393(31)$ & $5.57(4.38-7.09)$ & $4.97(3.79-6.51)$ \\
\hline \multicolumn{4}{|l|}{1 y prediagnosis specialty care } \\
\hline None & $151(12)$ & Ref & Ref \\
\hline PCP only & $637(51)$ & $0.94(0.78-1.13)$ & $0.83(0.67-1.03)$ \\
\hline GE/Hepatology & $462(37)$ & $0.68(0.56-0.83)$ & $0.74(0.58-0.94)$ \\
\hline \multicolumn{4}{|l|}{ Hematology/Oncology consult } \\
\hline No & $562(45)$ & Ref & Ref \\
\hline
\end{tabular}

Abbreviations: aHR, adjusted hazard ratio; CCl, Charlson-Deyo comorbidity index; GE, gastroenterology; HR, hazard ratio; LRT, locoregional therapies; PCP, primary care physician; TACE, transarterial chemoembolization; Y90, yttrium-90.

aModel was also adjusted for sex, marital status, cause of liver disease, prediagnosis healthcare utilization, prediagnosis alpha fetoprotein screening, surgical or GE/ hepatology consult in 90 days of diagnosis, $\mathrm{NCl}$ center or liver transplant center visit in 90 days after diagnosis, and county-level economic, rurality, and health services disadvantage indices, which were not significantly associated with survival with minimal/no trend suggesting possible effect. These variables were omitted to condense the table size.

aged $>65$ years are being listed for transplantation, ${ }^{31}$ and the negative associations between Medicare insurance and transplant center visits and survival persisted in multivariable models adjusting for age. Patients with Medicare and Medicaid had a 24\% and 57\% increased risk of death, respectively, compared with those with private insurance; this risk was $67 \%$ higher for those who were uninsured. The effect of insurance status on survival did not diminish after adjusting for patient age, comorbidity, and treatment, with a $58 \%$ and $55 \%$ increase in risk of death for patients with Medicare and Medicaid, respectively. The influence of public insurance on outcomes could reflect limitations imposed by Medicare and Medicaid on access to care; however, public insurance in this analysis is also likely a proxy for individual socioeconomic resources, given that income limits for North Carolina Medicaid are strict. ${ }^{32}$ Regardless of county resources, individuals with Medicare or Medicaid likely face additional financial challenges that could compromise access compared with their privately insured counterparts. The marked and persistently inferior outcomes among patients who were single, divorced/separated, or widowed (ie, advanced stage at presentation, less consultative care and treatment) and those with psychiatric comorbidity (ie, lower rates of treatment and inferior survival) also speak to the importance of individual resources (eg, social support) on the ability of patients with HCC to receive the care they need.

This study is strengthened by its large populationbased sample and the availability of linked insurance claims, allowing for the simultaneous exploration of patient, treatment, and facility factors on outcomes. However, this study must be interpreted in the context of potential limitations. First, the survival analysis was limited to patients who survived the 90-day treatment exposure window after diagnosis. Although this restriction was necessary to evaluate the effect of treatment on 


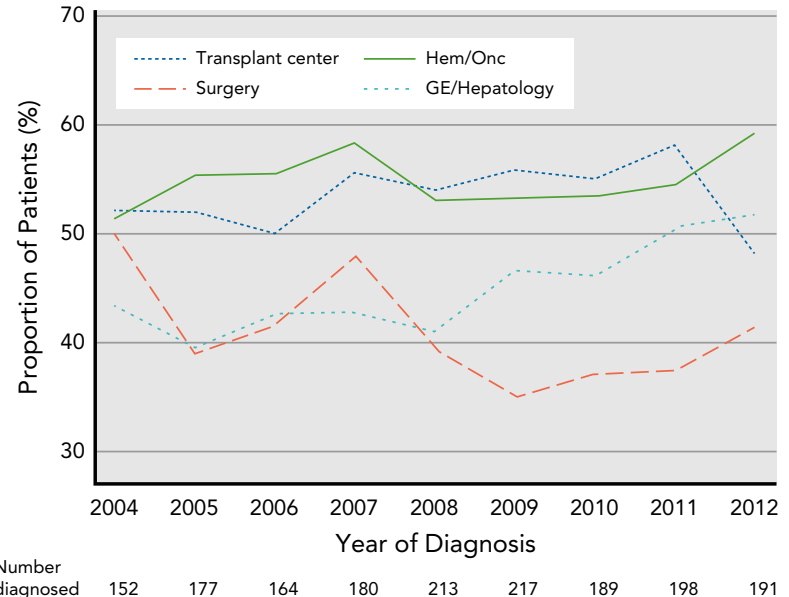

Figure 1. Time trends of subspecialty consultation within 90 days of diagnosis among incident patients with HCC diagnosed between 2004 and 2012.

Abbreviations: GE, gastroenterology; $\mathrm{HCC}$, hepatocellular carcinoma; Hem/Onc, hematology/oncology.

survival, omitting these sickest patients may have obscured the effect of county economic and healthcare factors on HCC outcomes. Although we generally found that the same factors that were associated with treatment were associated with early mortality (ie, age $>65$ years and cancer stage, greater comorbidity, single/divorced/ separated status, Medicare/Medicaid insurance, less prediagnostic care), a potentially meaningful difference was that patients with early mortality were more likely to live in a county with fewer healthcare services and lower density of gastroenterology/hepatology physicians. Second, the data source did not allow for adjustment for liver disease severity via the Model for End-Stage Liver Disease or Child-Pugh score, although we did account for prediagnosis liver-related complications. Finally, our data source did not allow us to assess for factors that could have contributed to improved survival over time, including improved treatments for underlying liver disease (eg, directacting antiviral therapy for hepatitis $\mathrm{C}$ virus), expanded access to HCC therapies and clinical trials, and broader adoption of multidisciplinary tumor boards and clinics.

\section{Conclusions}

Our findings that an individual's use of the healthcare system before diagnosis and visits to an expert center early during the cancer course are major driving forces behind treatment and survival for HCC are critical when considering how to improve outcomes of patients with HCC - both in North Carolina and across the nation. To reduce the rates of very early mortality from HCC, public health efforts must focus on detection of cirrhosis

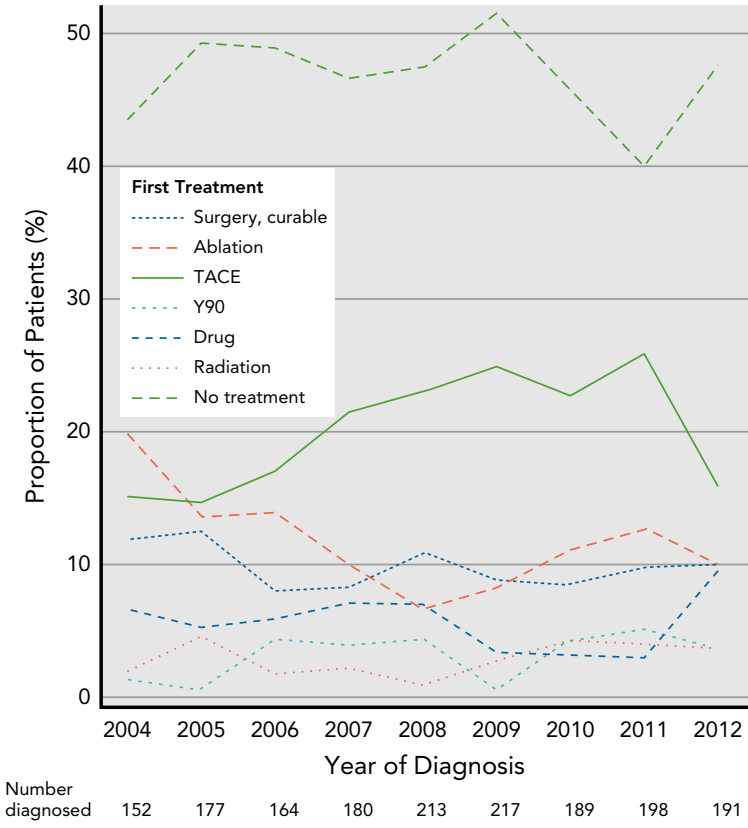

Figure 2. Time trends of type of initial treatment received by year of diagnosis among incident patients with $\mathrm{HCC}$ diagnosed between 2004 and 2012. Most patients diagnosed with HCC received no treatment every year during the study period.

Abbreviations: HCC, hepatocellular carcinoma; TACE, transarterial chemoembolization; Y90, yttrium-90.

and gastroenterology/hepatology referrals for affected individuals. To improve survival among patients who present earlier in their disease course, efforts must focus on increasing access to subspecialty care and treatment. Our ongoing work will examine patient-reported barriers to accessing care after an HCC diagnosis, with a focus on high-risk Black and rural residents and Medicare and Medicaid beneficiaries.

Submitted February 4, 2020; accepted for publication July 1, 2020 Published online February 12, 2021

Author contributions: Study concept and design: Sanoff, Chang, Lund, Barritt, Hayashi, Stitzenberg. Data interpretation: All authors. Statistical analysis: Chang. Drafting of manuscript: Sanoff. Critical revision: All authors.

Disclosures: Dr. Sanoff has disclosed that she has received grant/research support from Bayer. Dr. Lund has disclosed that her spouse is employed by GlaxoSmithKline. Dr. Barritt has disclosed that he has received grant/research support from Intercept Pharmaceuticals, Genfit Pharmaceuticals, Bristol-Myers Squibb, NuSirt, and Target Pharmasolutions. The remaining authors have disclosed that they have not received any financial consideration from any person or organization to support the preparation, analysis, results, or discussion of this article.

Funding: Research reported in this article was supported by the $\mathrm{NCl}$ of the $\mathrm{NIH}$ under award number K07CA160722 (H.K.S.) and by the NIH under award number T32 DK007634 (A.M.M.). The content is solely the responsibility of the authors and does not necessarily represent the official views of the $\mathrm{NIH}$. Additional support was provided by the Cancer Information \& Population Health Resource, UNC Lineberger Comprehensive Cancer Center, with funding provided by the University Cancer Research Fund via the State of North Carolina.

Correspondence: Hanna K. Sanoff, MD, MPH, University of North Carolina, Division of Hematology/Oncology, Department of Medicine, 170 Manning Drive, CB 7305, Chapel Hill, NC 27599. Email: hanna_sanoff@med.unc.edu 


\section{References}

1. White $D L$, Thrift AP, Kanwal F, et al. Incidence of hepatocellular carcinoma in all 50 United States, from 2000 through 2012. Gastroenterology 2017; 152:812-820.e5.

2. Petrick JL, Kelly SP, Altekruse SF, et al. Future of hepatocellular carcinoma incidence in the United States forecast through 2030. J Clin Oncol 2016; 34:1787-1794.

3. Kohler BA, Sherman RL, Howlader N, et al. Annual report to the nation on the status of cancer, 1975-2011, featuring incidence of breast cancer subtypes by race/ethnicity, poverty, and state. J Natl Cancer Inst 2015; 107:djv048.

4. El-Serag HB, Siegel AB, Davila JA, et al. Treatment and outcomes of treating of hepatocellular carcinoma among Medicare recipients in the United States: a population-based study. J Hepatol 2006;44: 158-166.

5. Sanoff HK, Chang Y, Stavas JM, et al. Effectiveness of initial transarterial chemoembolization for hepatocellular carcinoma among Medicare beneficiaries. J Natl Compr Canc Netw 2015;13:1102-1110.

6. Davila JA, Kramer JR, Duan Z, et al. Referral and receipt of treatment for hepatocellular carcinoma in United States veterans: effect of patient and nonpatient factors. Hepatology 2013;57:1858-1868.

7. Shah SA, Smith JK, Li Y, et al. Underutilization of therapy for hepatocellular carcinoma in the Medicare population. Cancer 2011;117:1019-1026.

8. Lopez PM, Villanueva A, Llovet JM. Systematic review: evidence-based management of hepatocellular carcinoma-an updated analysis of randomized controlled trials. Aliment Pharmacol Ther 2006:23:1535-1547.

9. Wang J, Ha J, Lopez A, et al. Medicaid and uninsured hepatocellular carcinoma patients have more advanced tumor stage and are less likely to receive treatment. J Clin Gastroenterol 2018;52:437-443.

10. Mokdad AA, Zhu H, Marrero JA, et al. Hospital volume and survival after hepatocellular carcinoma diagnosis. Am J Gastroenterol 2016; 111:967-975

11. Tan D, Yopp A, Beg MS, et al. Meta-analysis: underutilisation and disparities of treatment among patients with hepatocellular carcinoma in the United States. Aliment Pharmacol Ther 2013;38:703-712.

12. Artinyan A, Mailey B, Sanchez-Luege N, et al. Race, ethnicity, and socioeconomic status influence the survival of patients with hepatocellular carcinoma in the United States. Cancer 2010;116:1367-1377.

13. Davila JA, El-Serag HB. Racial differences in survival of hepatocellular carcinoma in the United States: a population-based study. Clin Gastroenterol Hepatol 2006;4:104-110.

14. Siegel AB, McBride RB, El-Serag HB, et al. Racial disparities in utilization of liver transplantation for hepatocellular carcinoma in the United States, 1998-2002. Am J Gastroenterol 2008;103:120-127.

15. Davila JA, Duan Z, McGlynn KA, et al. Utilization and outcomes of palliative therapy for hepatocellular carcinoma: a population-based study in the United States. J Clin Gastroenterol 2012;46:71-77.

16. Rich NE, Hester $\mathrm{C}$, Odewole $\mathrm{M}$, et al. Racial and ethnic differences in presentation and outcomes of hepatocellular carcinoma. Clin Gastroenterol Hepatol 2019;17:551-559.e1.
17. Serper M, Taddei TH, Mehta R, et al. Association of provider specialty and multidisciplinary care with hepatocellular carcinoma treatment and mortality. Gastroenterology 2017;152:1954-1964.

18. Meyer AM, Olshan AF, Green L, et al. Big data for population-based cancer research: the integrated cancer information and surveillance system. N C Med J 2014;75:265-269.

19. Forner A, Reig ME, de Lope CR, et al. Current strategy for staging and treatment: the BCLC update and future prospects. Semin Liver Dis 2010;30:61-74

20. Llovet JM, Brú C, Bruix J. Prognosis of hepatocellular carcinoma: the BCLC staging classification. Semin Liver Dis 1999;19:329-338.

21. Health Resources \& Services Administration. Area Health Resources Files Accessed July 28, 2020. Available at: http://data.hrsa.gov/topics/healthworkforce/ahrf

22. Yu M, Tatalovich Z, Gibson JT, et al. Using a composite index of socioeconomic status to investigate health disparities while protecting the confidentiality of cancer registry data. Cancer Causes Control 2014;25:81-92.

23. Yost K, Perkins C, Cohen R, et al. Socioeconomic status and breast cancer incidence in California for different race/ethnic groups. Cancer Causes Control 2001;12:703-711.

24. Krieger N, Chen JT, Waterman PD, et al. Geocoding and monitoring of US socioeconomic inequalities in mortality and cancer incidence: does the choice of area-based measure and geographic level matter? The Public Health Disparities Geocoding Project. Am J Epidemiol 2002;156: 471-482.

25. Klabunde CN, Potosky AL, Legler JM, et al. Development of a comorbidity index using physician claims data. J Clin Epidemiol 2000 53:1258-1267.

26. Ulahannan SV, Duffy AG, McNeel TS, et al. Earlier presentation and application of curative treatments in hepatocellular carcinoma. Hepatology 2014;60:1637-1644.

27. Davila JA, Morgan RO, Richardson PA, et al. Use of surveillance for hepatocellular carcinoma among patients with cirrhosis in the United States. Hepatology 2010;52:132-141.

28. Bruix J, Sherman M. Management of hepatocellular carcinoma: an update. Hepatology 2010;53:1020-1022.

29. Shebl FM, Capo-Ramos DE, Graubard BI, et al. Socioeconomic status and hepatocellular carcinoma in the United States. Cancer Epidemiol Biomarkers Prev 2012;21:1330-1335.

30. Chang ET, Yang J, Alfaro-Velcamp T, et al. Disparities in liver cancer incidence by nativity, acculturation, and socioeconomic status in California Hispanics and Asians. Cancer Epidemiol Biomarkers Prev 2010;19:3106-3118.

31. Cullaro G, Rubin JB, Mehta N, et al. Differential impact of age among liver transplant candidates with and without hepatocellular carcinoma. Liver Transpl 2020;26:349-358.

32. NC Medicaid Division of Health Benefits. Eligibility for Medicaid or Health Choice. Accessed July 28, 2020. Available at: http://medicaid.ncdhhs. gov/beneficiaries/get-started/eligibility-medicaid-or-health-choice 
Supplemental online content for:

\section{Medicare/Medicaid Insurance, Rurality, and Black Race Associated With Provision of Hepatocellular Carcinoma Treatment and Survival}

Andrew M. Moon, MD, MPH; Hanna K. Sanoff, MD, MPH; YunKyung Chang, PhD; Jennifer L. Lund, PhD; A. Sidney Barritt IV, MD, MSCR; Paul H. Hayashi, MD, MPH; and Karyn B. Stitzenberg, MD, MPH

J Natl Compr Canc Netw 2021;19(3):285-293

eFigure 1: CONSORT Diagram of Cohort Assembly

eTable 1: Factor Analysis for Area-Level Indices

eTable 2: Patient Characteristics

eTable 3: Association of Stage at Presentation and Transplant Center Visit With Patient- and Area-Level Factors 
HCC diagnosed in North Carolina from 2003-2013

ICD-10 code C22.0 and ICD-O-3 histology codes 8170-8175, 8180 $(\mathrm{N}=4,465)$

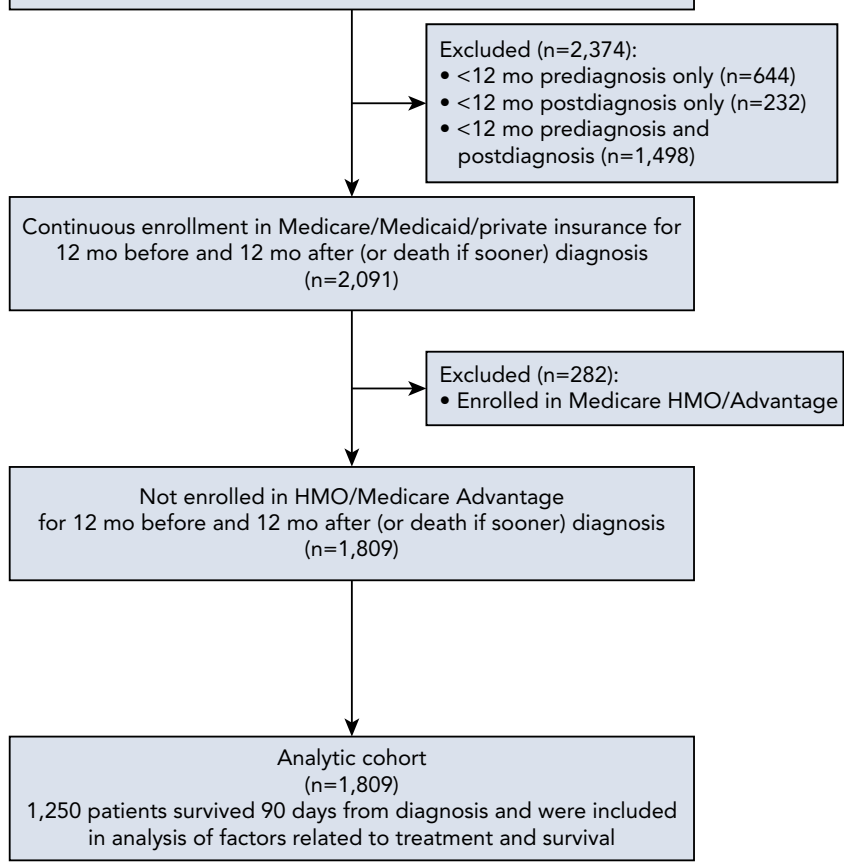

eFigure 1. CONSORT diagram of cohort assembly.

Abbreviation: HCC, hepatocellular carcinoma. 


\section{eTable 1. Factor Analysis for Area-Level Indices}

\begin{tabular}{|c|c|c|c|}
\hline Variable & Economic Index & Rurality Index & Healthcare Index \\
\hline Median home value & 0.78567 & -0.16994 & NA \\
\hline Percentage of White patients & 0.74240 & 0.00694 & NA \\
\hline Median household income & 0.56927 & -0.52099 & NA \\
\hline Percentage of uninsured patients aged $<65$ years & 0.53235 & 0.51554 & NA \\
\hline Persistent poverty & -0.49136 & 0.17469 & NA \\
\hline Lower education level ( $>25 \%$ without high school) & -0.60946 & 0.24739 & NA \\
\hline High poverty & -0.69429 & 0.44694 & NA \\
\hline Unemployment rate, age $\geq 16$ years & -0.73858 & 0.10738 & NA \\
\hline Rural-Urban Continuum Codes & -0.16917 & 0.77060 & NA \\
\hline Percentage agriculture/forestry/fishing/hunting/mining industries & -0.28463 & 0.59780 & NA \\
\hline Percentage of Hispanic patients & -0.01373 & -0.02848 & NA \\
\hline Percentage of variance explained & 54.9 & 28.3 & NA \\
\hline Internal medicine subspecialties, total patient care per 100,000 population & NA & NA & 0.83506 \\
\hline Psychiatric care per 100,000 population & NA & NA & 0.80305 \\
\hline Primary care physicians per 100,000 population & NA & NA & 0.73967 \\
\hline Short-term hospital beds per 100,000 population & NA & NA & 0.65049 \\
\hline Percentage of variance explained & NA & NA & 57.8 \\
\hline
\end{tabular}

Abbreviation: NA, not applicable. 


\section{eTable 2. Patient Characteristics $(N=1,809)$}

\begin{tabular}{|c|c|}
\hline Characteristic & n (\%) \\
\hline \multicolumn{2}{|l|}{ Cancer extent } \\
\hline Single without vascular invasion & $671(37)$ \\
\hline Single with vascular invasion & $105(6)$ \\
\hline Multiple without vascular invasion & $458(25)$ \\
\hline Multiple with vascular invasion & $230(13)$ \\
\hline Extrahepatic & $66(4)$ \\
\hline Not staged & $279(15)$ \\
\hline Median age (IQR), y & $68(59-76)$ \\
\hline$<50 y$ & $110(6)$ \\
\hline $50-64$ y & $574(32)$ \\
\hline $65-74 y$ & $611(34)$ \\
\hline$\geq 75$ y & $514(28)$ \\
\hline \multicolumn{2}{|l|}{ Sex } \\
\hline Male & $1,326(73)$ \\
\hline Female & $483(27)$ \\
\hline \multicolumn{2}{|l|}{ Race } \\
\hline White & $1,375(76)$ \\
\hline Black & $368(20)$ \\
\hline Asian & a \\
\hline Native American & a \\
\hline Other & $66(4)$ \\
\hline \multicolumn{2}{|l|}{ Marital status } \\
\hline Married & $803(44)$ \\
\hline Widowed & $33(2)$ \\
\hline Divorced/Separated/Single & $640(35)$ \\
\hline Other/Unknown & $333(18)$ \\
\hline \multicolumn{2}{|l|}{ Insurance at diagnosis } \\
\hline Private & $165(9)$ \\
\hline Medicare & $1,069(59)$ \\
\hline Medicaid/Dual & $575(32)$ \\
\hline Tricare/VA & $N A^{b}$ \\
\hline Other & $N A^{b}$ \\
\hline Uninsured & $N A^{b}$ \\
\hline
\end{tabular}

(continued)

\section{eTable 2. Patient Characteristics $(N=1,809)$ (cont.)}

Characteristic

n (\%)

Psychiatric comorbidity

\begin{tabular}{ll}
\hline Yes & $820(45)$ \\
\hline No & $989(55)$
\end{tabular}

$\mathrm{CCl}$ score

\begin{tabular}{ll}
0 & $657(36)$ \\
\hline 1 & $526(29)$ \\
$\geq 2$ & $626(35)$
\end{tabular}

Liver-related complications

\begin{tabular}{lr}
0 & $1,107(61)$ \\
\hline 1 & $702(39)$
\end{tabular}

$\geq 1$

702 (39)

Cause of liver disease ${ }^{c}$

\begin{tabular}{lc}
\hline Hepatitis B virus & $96(5)$ \\
\hline Hepatitis C virus & $538(30)$ \\
\hline Alcohol & $306(17)$ \\
\hline Other cause of cirrhosis & $371(21)$
\end{tabular}

County economic disadvantage index

\begin{tabular}{ll}
\hline Q1: least disadvantaged & $352(19)$ \\
\hline Q2 & $645(36)$ \\
\hline Q3 & $595(33)$ \\
\hline Q4: most disadvantaged & $216(12)$
\end{tabular}

County rurality index

\begin{tabular}{ll}
\hline Q1: least rural & $953(53)$ \\
\hline Q2 & $433(24)$ \\
\hline Q3 & $290(16)$ \\
Q4: most rural & $132(7)$
\end{tabular}

County healthcare disadvantage index

\begin{tabular}{ll}
\hline Q1: least disadvantaged & $897(50)$ \\
\hline Q2 & $389(22)$ \\
\hline Q3 & $308(17)$ \\
\hline Q4: most disadvantaged & $214(12)$ \\
\hline
\end{tabular}

Abbreviations: $\mathrm{CCl}$, Charlson-Deyo Comorbidity Index; IQR, interquartile range; NA, not available; Q, quartile; VA, U.S. Department of Veterans Affairs. aTo preserve confidentiality, table cells representing $<11$ individuals were not included.

${ }^{b}$ Claims not available for these insurers.

cCauses of liver disease are not mutually exclusive and will not sum to $100 \%$. 


\section{eTable 3. Association of Stage at Presentation and Transplant Center Visit With Patient-} and Area-Level Factors

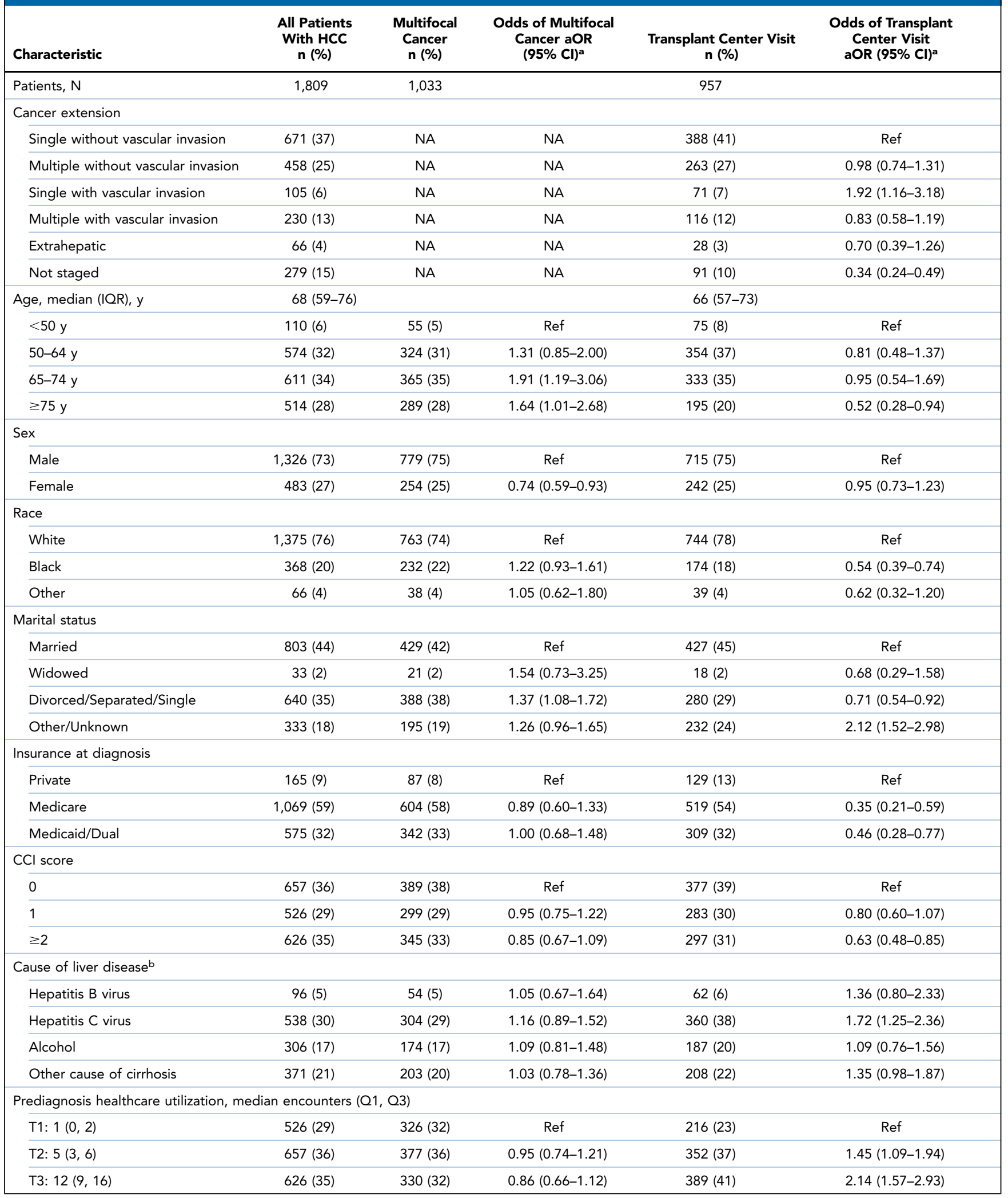




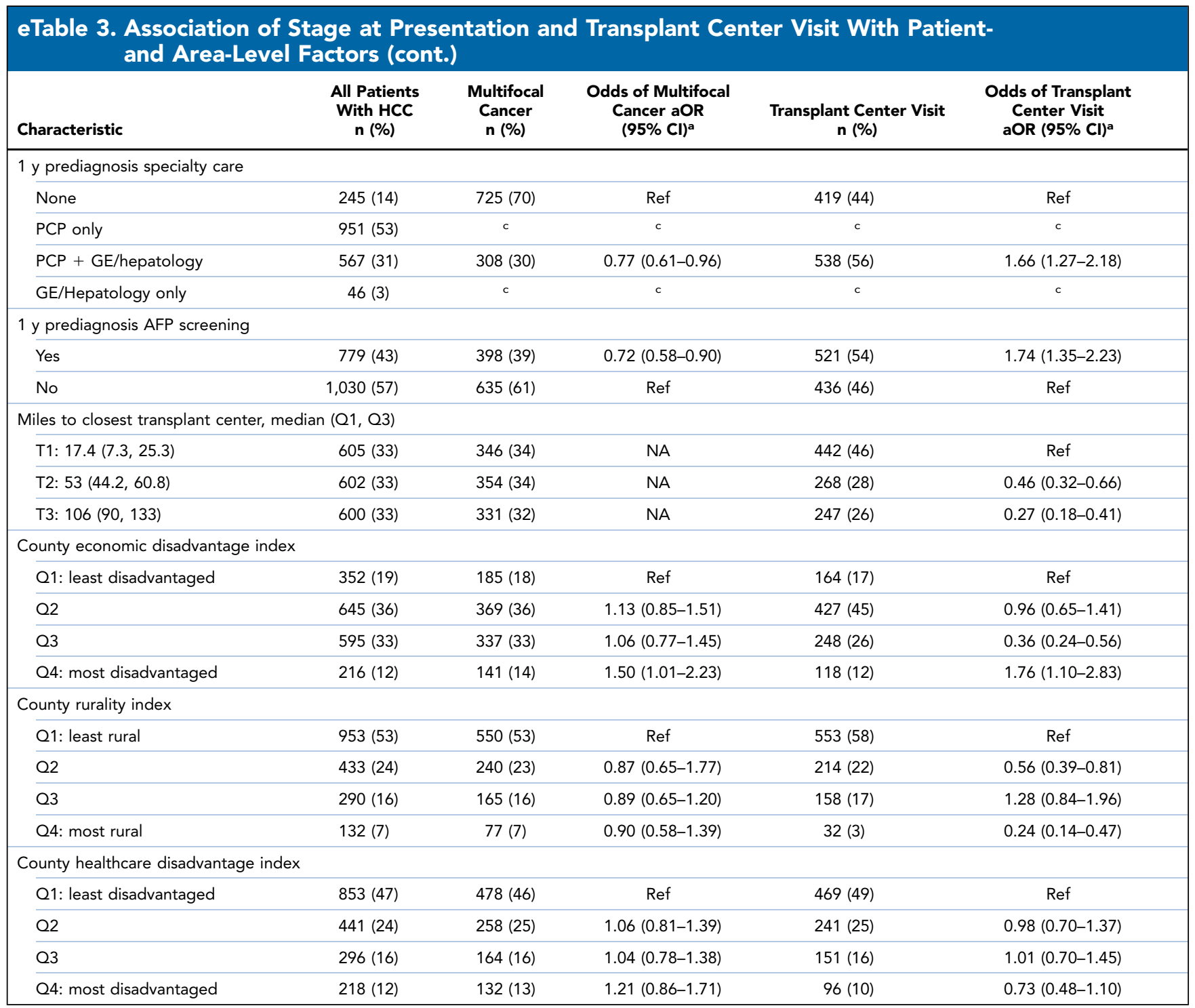

Abbreviations: AFP, alpha fetoprotein; aOR, adjusted odds ratio; CCl, Charlson-Deyo comorbidity index; GE, gastroenterology; HCC, hepatocellular carcinoma; IOR, interquartile ratio; NA, not available; $P C P$, primary care physician; $T$, tertile; $Q$, quartile.

aModel was also adjusted for psychiatric comorbidity, liver comorbidity (complications of cirrhosis), and number of hepatologists per 100,000 population, which was not significantly associated with survival with minimal/no trend suggesting possible effect. These variables were omitted to condense the table size.

${ }^{b}$ Causes of liver disease are not mutually exclusive and will not sum to $100 \%$.

"Cells combined with cell above for multivariable model, comparing "any GI/hepatology" to referent of "none" or "PCP only." 